
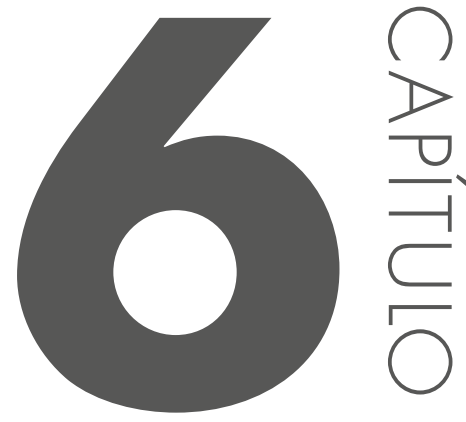

\title{
- ETHOS DISCURSIVO NA SALA DE BATE-PAPO 11 UOL46/SALVADOR-BA ON-LINE, HOMOAFETIVO; OFF-LINE, HETERONORMATIVO
}

\section{Gilberto Nazareno Telles Sobral* Valter Cezar Andrade Junior**}

* Doutor em Letras. Professor titular da Universidade do Estado da Bahia - UNEB. E-mail: gsobral@uneb.br

* Mestrando no Programa de Pós-graduação em Estudo de Linguagens - PPGEL, da Universidade do Estado da Bahia - UNEB, orientado pelo Professor Doutor Gilberto Nazareno Telles Sobral. É professor de Língua Portuguesa no IF-Sertão Pernambucano. E-mail: valter_cezar@hotmail.com

\footnotetext{
${ }^{46}$ Site de notícias e diversidade, juridicamente instituído como Universo On-Line (UOL). Endereço: www.vol.com.br
} 


\section{Introduc̣ão}

Inegavelmente, nos últimos anos, as sociedades têm passado por transformações no campo dos comportamentos de forma rápida e acentuadamente diversa. Ora, essa experimentação se dá num momento, para este estudo, denominado de Pós-modernidade, cujas bases se assentam na rapidez das transformações.

Segundo Teixeira Coelho (1995, p. 46), em termos cronológicos, "a Pós-Modernidade teria início com o final da Segunda Guerra Mundial, que marca a era da TV, dos tempos da saúde pós-penicilina (...)". A PósModernidade é caracterizada pelo panteísmo, em que o que importa é a fé pela fé, ou seja, tudo pode ser deus, dependendo apenas do acreditar 
individual; o homem é gnóstico, pois possui em si essência do divino, que - faz também parte física dessa dada entidade divina. É a época pósindustrial, a qual funciona como responsável da expansão do industrialismo aos países atrasados, colocando-os na condição de emergentes, bem como o advento de avanços tecnológicos àqueles já industrializados.

Nesse novo paradigma, mediado pela tecnologia dos códigos binários, surge este trabalho, à luz do uso da linguagem - e consequente discursividade - em ambiente virtual, como forma de análise da construção do ethos discursivo homoafetivo, observando, ainda, o transitar pela construção, também e paralelamente, do ethos discursivo heteronormativo. Daí surgiu o interesse por esse trabalho, posto que as salas de batepapo da UOL fornecem material discursivo suficiente para sustentar a pesquisa aqui apresentada. Lévy (2000, p.44) diz sobre o universo on-line:

O computador não é mais um centro, e sim um nó, um terminal, um componente da rede universal calculante. Suas funções pulverizadas infiltram cada elemento do tecno-cosmos. No limite há apenas um único computador, mas é impossível traçar seus limites, seu contorno. É um computador cujo centro está em toda parte e a circunferência em lugar algum, um computador hipertextual, disperso, vivo, fervilhante, inacabado: o ciberespaço em si.

Observe-se, ainda, que, na Pós-modernidade, há um determinante de esvaziamento dos valores e regras, desfazendo princípios, práticas e realidades - aqui também se assenta o cerne dessa pesquisa, na medida em que se pode observar como a sociedade é mutável e passa a estabelecer novos critérios de aceitação, ou não, daquilo que lhe é legitimo. É, portanto, um paradigma que mistura várias tendências e estilos, configurandose pluralidade e completa abertura. Em consequência disso, a época contemporânea busca empreender a escuta das vozes esquecidas que, no processo de esmagamento da diversidade, eram abafadas pelos mecanismos camuflados de opressão. Torna-se cada vez mais necessária a procura de geografias que não excluam as margens prolíferas do heterogêneo. 


\section{Considerações sobre ethos}

Para este artigo, é interessante trazer à baila algumas considerações sobre ethos, desde a Antiguidade Clássica até a contemporaneidade. Para tanto, parte-se do conceito aristotélico até aportar no deslocamento proposto Maingueneau para a Análise de Discurso de filiação francesa (doravante ADFF).

Sabe-se que, para persuadir o outro, o enunciador deve, pelo discurso, construir uma imagem de si mesmo, imagem tal, criada e mostrada no momento da enunciação. Sobral e Miranda (2013, p. 29) afirmam que "o ethos, enquanto imagens do sujeito do discurso, é fundamental para validar toda enunciação".

Na Retórica aristotélica, como afirma Osakabe (1979, p.141), "o caráter do orador é colocado em ação pela fala, isto é, enquanto orador, a fala é o único meio válido para que possa atingir sua finalidade de persuadir." O orador, então, é incorporado pelo ethos, uma vez que o grau de credibilidade é uma função de seu caráter e da confiança a ele atribuída pelo auditório. Ressalta-se que essa imagem não significa que seja a imagem mesma do orador, como ente no mundo, ser jurídico. Fica claro, então, que, para os gregos, o ethos é uma construção discursiva.

Já os romanos, diz Amossy (2005, p.17), "[...] consideravam o ethos como um dado pré-existente, que se apoia na autoridade individual e institucional do orador (a reputação de sua família, seu estatuto social, o que se sabe de seu modo de vida etc.)", donde se pode asseverar tratar-se de uma categoria pré-discursiva. Ressalte-se, no entanto, que o pensamento grego sobre ethos prevalece nos estudos linguísticos atuais.

No encaminhamento, observe-se que a noção de ethos chega à ADFF acrescida, no entanto, de um sujeito que, diferente do cartesiano da Pragmática, não é mais a origem do dizer, revisando o próprio caráter do ethos. O sujeito autônomo, dono de si, da Pragmática, na ADFF, é substituído por um assujeitado à linguagem, subjugado às muitas ideologias que circulam na sociedade.

Maingueneau (2002), por exemplo, propõe um duplo deslocamento à noção de ethos: o orador não mais define o tom do discurso em função dos efeitos que pretendia produzir em seu auditório, como na Retórica Antiga, pois este não possui o controle de seu discurso, uma vez que o tom é produzido pela formação discursiva em que está inserido; o outro deslocamento é que se a Retórica Antiga voltava-se ao discurso oral, a noção de ethos passa a ser aplicada ao texto oral e escrito. Conforme Maingueneau (2002, p. 98), 
texto escrito possui, mesmo quando o denega, um tom que dá autoridade ao que é dito. Esse tom permite ao leitor construir uma representação do corpo do enunciador (e não, evidentemente, do corpo do autor efetivo). A leitura faz, então, emergir uma instância subjetiva que desempenha o papel de fiador do que é dito.

Desta forma, a figura do fiador constrói-se a partir dos indícios textuais, a quem, ainda segundo o autor $(2002,98)$, "são atribuídos um caráter e uma corporalidade. [...] O caráter corresponde a uma gama de traços psicológicos. Já a corporalidade corresponde a uma compleição corporal, mas também a uma maneira de se vestir e de se movimentar no espaço social".

Ora, como o enunciador não depende unicamente de si para constituição de seu ethos - tampouco o coenunciador depende unicamente de si para tanto, mas também do enunciador-, ocorre, dessa forma, por via da atribuição de imagem em interação, de forma que ambos trazem para o ambiente da discursividade marcas sociais e históricas.

Através do estilo próprio, da competência linguística e, principalmente, dos valores e crenças que se materializam no discurso, constrói-se uma representação daquele que enuncia, o que constitui importante fator de influência sobre o outro. Destaca-se, ainda, que as diversas formas de apresentar-se estão diretamente interligadas aos diversos papéis sociais assumidos por um indivíduo, que o constituem sujeito. (SOBRAL e MIRANDA, 2013, p. 29).

Tais marcas, pois, o constituem e aparecem na enunciação através do que Maingueneau e Charaudeau (2004, p.213) chamaram de estereótipo: "estereotipado designa, do mesmo modo, o que é fixo, cristalizado", podendo ainda ser compreendido como "imagens prontas, que medeiam a relação do indivíduo com a realidade". Também como "representações coletivas cristalizadas, crenças pré-concebidas, frequentemente nocivas a grupos ou a indivíduos".

Em face disso, pode-se dizer também que o coenunciador constrói o ethos do enunciador, sendo igualmente criado por intermédio de um dado estereótipo. Sendo assim, o enunciador deve se adaptar aos coletivos percebidos por ele a partir do coenunciador (particular ou coletivo). Isto por 
que, reiterando, o ethos deve influenciar o parceiro no processo discursivo, num retorno ao dito aristotélico. Como afirma Maingueneau (2008, p. 13),

\section{a prova pelo ethos consiste em causar boa impressão pela forma como se constrói o discurso, a dar uma imagem de si capaz de convencer o auditório, ganhando sua confiança. $\bigcirc$ destinatário deve, então, atribuir certas propriedades à instância que é posta como fonte do acontecimento enunciativo.}

Fica posto que o ethos é uma experiência sensível do discurso, não sendo, pois, uma representação estática (MAINGUENEAU, 2008, p. 14). Donde se tira, então, que persuadir é fazer passar pelo discurso um ethos característico do coenunciador. Por esse turno, "o ethos se elabora, assim, por meio de uma percepção complexa, mobilizadora da afetividade do intérprete, que tira suas informações do material linguístico e do ambiente" (MAINGUENEAU, 2008, p.16). Logo, deve-se levar em conta que, muitas vezes, o ethos visado não é o ethos produzido. Sobre isso, na nova Retórica, Perelman; Olbrechts-Tyteca (2005) disseram da necessidade que o orador tem de se adaptar ao seu auditório em função das crenças e valores dos que ouvem; no caso do corpus desse artigo, dos que leem.

Dentro da categoria de ethos discursivo - foco desse artigo -, Maingueneau (2008) traz dois conceitos: 1. ethos dito; e 2. ethos mostrado. $O$ dito é referência direta ao enunciador, enquanto o mostrado é revelado pelo não explícito, sem representação direta no texto.

Até aqui já é suficiente para tomar posse desses conceitos de ethos (sobretudo os de Maingueneau) e suas interfaces, a fim de seguir um processo analítico dos diálogos que se seguem, retirados da sala de bate-papo 11 do UOL, Salvador/BA.

\section{Da construc̣ão do ethos}

\section{homoafetivo e heteronormativo na sala de bate-papo 11 do UOL, Salvador/BA}

Há muito, questões relativas à sexualidade humana inquietam pesquisadores, religiosos, pessoas comuns. Não nos parece demais essa inquietação, posto que representa legitimações do indivíduo em seu núcleo 
social, admitindo-o dentro da concepção de normalidade do sexo ou, ainda, de natural. Sobre isso, Butler (2000) acena para um pensamento fundante que é de uma sexualidade, em tese, sempre heterossexual. Fica claro, para qualquer um, que as instâncias sociais insistem em legitimar apenas a heterossexualidade, admitindo, biologicamente, inclusive, que só há homem e mulher em relação natural sexual, correlacionando para isso os gêneros masculino e feminino. Não há, pois, variantes. Disso, tiramos que há uma clara alusão à questão sexual presa, primeiramente, ao material, donde se justificam as diferenças:

[...] a diferença sexual é frequentemente evocada como uma questão referente a diferenças materiais. A diferença sexual, entretanto, não é, nunca, simplesmente, uma função de diferenças materiais que não sejam, de alguma forma, simultaneamente marcadas e formadas por práticas discursivas (BUTLER, 2000, p. 151).

Partindo desse princípio é que seguiremos a análise identificando na materialidade discursiva a construção do ethos do sujeito heteronormativo e do sujeito homoafetivo na sala de bate-papo. Para melhor compreensão do diálogo, importante clarificar que "De boa" é o nickname utilizado pelo enunciador e que o nickname "CASADO-40-BA" é o utilizado pelo coenunciador. Entenda-se como enunciador aquele que desenvolve a pesquisa do tipo participada, posto que se inseriu na sala de bate-papo a fim de empreender diálogo com os sujeitos ali presentes. Por coenunciador, entenda-se o sujeito pesquisado, tendo sido escolhido por, dentre outros que ali estavam, trazer uma construção de si que transita dentro de duas matrizes sexuais dispostas nesta pesquisa: homossexual e heteronormativa.

Nesse estudo, mapeia-se como se dá o processo de argumentatividade, identificando como se organiza a teia argumentativa homoafetiva, relacionando-se sempre com o desejo de convencimento do contrário: da parte do enunciador há um trabalho com argumentos do universo homo; da parte do coenunciador, há uma tentativa de negação do ethos homo, mas deixa-se mostrado no uso de lexias comuns deste universo (estereótipo), como um processo de sensibilidade do ethos efetivamente construído pelo enunciador.

A começar pelo nickname "CASADO-40-BA", observa-se que já aí se pode fazer um gesto de leitura e construção de um ethos pré-discursivo, posto que ao enunciador é possível construir a imagem do coenunciador de 
um homem heterossexual, nos moldes da exigência social - portanto de um estereótipo -, de meia idade, morador da Bahia, cujo estado se reconhece pela vivacidade de seu povo. Logo, cria-se uma cena de virilidade machista, dentro dos moldes de um homem que se reserva à vida em família e que, por algum 'erro' de conduta, talvez, busque na sala de bate-papo virtual encontrar a natural e aceita 'pulada de cerca' do homem bem-casado. A ideia comum de que aos homens é permitida a traição e retorno ao lar com a manutenção de um bem-sucedido casamento.

Como se sabe, no universo on-line, os diálogos tendem a ser rápidos, natural velocidade constitutiva das tecnologias da informação contemporâneas. Em face disso, vê-se adiante que a abordagem inicial entre enunciador e coenunciador é igualmente rápida e direta nos objetivos (atentar que os diálogos foram dispostos exatamente da forma que foram desenvolvidos na sala de bate-papo, inclusive com desvios da norma escrita):

De boa (reservadamente) fala para CASADO-40-BA: Bom dia

CASADO-40-BA (reservadamente) fala para De boa: oi

CASADO-40-BA (reservadamente) fala para De boa: $\mathbf{h} \mathbf{u} \mathbf{~ m} ?$

De boa (reservadamente) fala para CASADO-40-BA: $\mathbf{h}$

De boa (reservadamente) fala para CASADO-40-BA: curte CASADO-40-BA (reservadamente) fala para De boa: se tiver mulher unto
(curto) sim

Observe-se que, no desenrolar do diálogo, o ethos de "homem de família", heterossexual e detentor de uma certa moral inabalável, é posto à prova, posto que o coenunciador se permite relacionar-se com outro homem, desde que haja a presença de uma mulher. Ora, aqui encontramos o dito anteriormente de que o ethos é mutável e que, nem sempre, o que o orador quer construir de si é exatamente aquilo que se expressa em sua discursividade. A confirmação está em: se tiver mulher unto sim (se tiver mulher, curto sim). $\bigcirc$ argumento da presença da mulher é a tentativa de manutenção, pelo ethos dito, do ethos mostrado, de que não há ali um acordo sexual entre iguais; o discursivo tentando manter o pré-discursivo; o visado pelo coenunciador em choque imagético com o efetivamente produzido pelo enunciador. 
Ainda no seguimento, temos a mudança, de fato, do ethos do coenunciador de homem viril e heterossexual:

De boa (reservadamente) fala para CASADO-40-BA: e se tiver mulher eu posso fazer o que com vc?

CASADO-40-BA (reservadamente) fala para De boa: menos me comer, rsss

De boa (reservadamente) fala para CASADO-40-BA: o resto rola na boa?

De boa (reservadamente) fala para CASADO-40-BA: sexo ora e tudo?

De boa (reservadamente) fala para CASADO-40-BA: beijos?

CASADO-40-BA (reservadamente) fala para De boa: com buceta junto sim, deixo me chupar, chupo, beijo fico doidão de tsão

Só se pode afirmar tal mudança do ethos, porque "CASADO-40-BA" admite discursivamente que só não se permite ser penetrado, algo que um heterossexual convicto - típico estereótipo de 'homem' - não aceitaria, posto que só se relaciona com o sexo oposto. A confirmação do ethos homossexual (com embalagem de bissexual) constrói-se quando o coenunciador admite sentir desejo pelo corpo masculino - embora só admita isso com a presença de uma mulher (no uso da lexia buceta, comum entre heteros - entre os homos, usa-se a lexia, com frequência, racha) para legitimar o ethos da masculinidade - asseverando que com buceta junto sim, deixo me chupar, chupo, beijo fico doidão de tsão. Ou seja, ele é capaz de fazer sexo oral em outro homem - conforme se lê no argumento construído pela lexia chupo -, porque, segundo ele, no momento se deixa levar pelo desejo, no caso, homoafetivo. Para fixar de vez o ethos homo, admite, ainda, beijar (beijo), o que para a construção de um ethos heterossexual é impraticável, já que é um toque, muitas vezes, acordado no estereótipo machista como sendo mais íntimo que a própria cópula; beijar é ato de entrega. Ainda a lexia doidão (como argumento) dá a convencer o enunciador de que pode ser bom, além de justificar 'perdão' pelo 'desvio' do ethos pré-discursivo hetero, uma vez que ser doido é estar fora da razão, longe da culpa, entregue à situação. 
Na sequência do diálogo entre enunciador e coenunciador, tem-se:

De boa (reservadamente) fala para CASADO-4O-BA: sua mulher nem sabe disso né man?

CASADO-4O-BA (reservadamente) fala para De boa: sabe não, eu já andei propondo ums (umas) coisas a ela, mais (mas) não teve jeito

Observa-se aí, por fim, que o enunciador quer se certificar se de fato o coenunciador é casado com mulher, posto que, tão rapidamente, admitiu estar disposto a uma relação sexual com outro homem. Ora, o argumento do enunciador é de confirmação ao assegurar que haja mesmo uma mulher na vida do coenunciador: sua mulher. Este, além de legitimar, lança um argumento de duplo convencimento: 1. para ele, o uso do pronome ela é o convencimento de que é possível ainda sustentar o ethos pré-discursivo de homem heterossexual; 2 . para o enunciador, a sentença de argumentos andei propondo umas coisas a ela é o convencimento de um ethos homoafetivo, envolto ainda na necessidade social (de um estereótipo heterossexista) de que ao homem apenas cabe ser 'macho', de única matriz sexual.

Fica disposta uma imagem do coenunciador de um sujeito que se prende à heteronormatividade, mas que se rende ao desejo pelo igual, de outra matriz sexual. Ainda que se tente estar sempre próximo à matriz hetero, deixa-se construir uma imagem de si, por via das lexias, de um homem que, mesmo afirmando-se casado e que busca relacionar-se com mulher, deixase viver relação homoafetiva. É, portanto, um coenunciador que se esmera em construir-se unilateral no desejo sexual, mas que se rende no diálogo à possibilidade - tendo mulher na relação, em seu dizer - relacionar-se sexualmente com outro homem. Cria-se por isso a imagem decerto difusa, mas igualmente latente de homem que se identifica muito mais com a matriz sexual bi. 


\section{Considerạ̣ões Finais}

Vê-se, portanto, que há certa complexidade na compreensão/ percepção da construção do ethos quando deslocamos para a ADFF, posto que há a influência do enunciador sobre o coenunciador (e vice-versa), dentro de um contexto que é linguageiro, mas que também o é sócio-histórico.

Nas análises precedentes, observou-se que nem sempre o ethos pretendido pelo coenunciador é conseguido no enunciador (podendo acontecer de forma inversa também, claro). Também se viu que a presença de estereótipos bem delineados no campo da sexualidade se conflitam, mesmo quando há um acordo entre as partes, no caso específico, a relação sexual. Há um jogo de forças argumentativas entre a tentativa do coenunciador de se manter no ethos pré-discursivo heterossexual, por via do ethos dito, e, ao mesmo tempo, do enunciador insistir em argumentar no campo esterotípico do ethos homoafetivo, respaldado pelo ethos mostrado. Certo fica, entretanto, que houve sim um acordo entre ambos: continuar a argumentação no campo da sexualidade, tendendo à satisfação (sexual) de ambos. 


\section{Referências Bibliográficas:}

ARISTÓTELES. Retórica. Introdução de Manuel Alexandre Júnior. Tradução e notas de Manuel Alexandre Júnior, Paulo Farmhouse Alberto e Abel do Nascimento Pena. Lisboa: Imprensa Nacional, Casa da Moeda, 1998.

AMOSSY, R. Da noção retórica de ethos à análise do discurso. In:

(Org.). Imagens de si no discurso, a construção do ethos. São Paulo: Contexto, 2005.

BUTLER, J. Problemas de gênero: feminismo e subversão da identidade. Rio de Janeiro: Editora Civilização Brasileira, 2003.

BUTLER, J. Corpos que pesam: sobre os limites discursivos do sexo. In: 0 corpo educado - pedagogias da sexualidade. Belo Horizonte: Autêntica, 2000, p. 151-176.

CHARAUDEAU, P.; MAINGUENEAU, D. Dicionário de análise do discurso. Coordenação da tradução Fabiana Komesu. São Paulo: Contexto, 2004.

COELHO, T. Moderno pós-moderno. 3. ed. São Paulo: lluminuras, 1995.

DUCROT, O. O dizer e o dito. Revisão técnica da tradução Eduardo Guimarães. Campinas: Pontes, 1997.

LÉVY, P. Cibercultura. Tradução Carlos Irineu da Costa. 2. ed. São Paulo: Ed. $34,2000$.

MAINGUENEAU, D. A propósito do ethos. In: Ethos discursivo. São Paulo: Contexto, 2008, p. 11-32.

OSAKABE, Haquira. Argumentação e discurso político. 2. ed. São Paulo: Martins Fontes, 1979.

PERELMAN, C.; OLBRECHTS-TYTECA, M. Tratado da argumentação: a nova Retórica. Tradução de Maria Ermantina Galvão G. Pereira. São Paulo: Martins Fontes, 2005. 
SOBRAL. G. N. T.; MIRANDA, R. A. de. A construção do ethos no jornal Massa!: uma identificação com a Cidade de Salvador. In: Salvador em preto e branco: estudos do discurso. Estudos Sociolinguísticos. Salvador: Quarteto, 2013 , p. $27-43$.

\section{Anexos:}

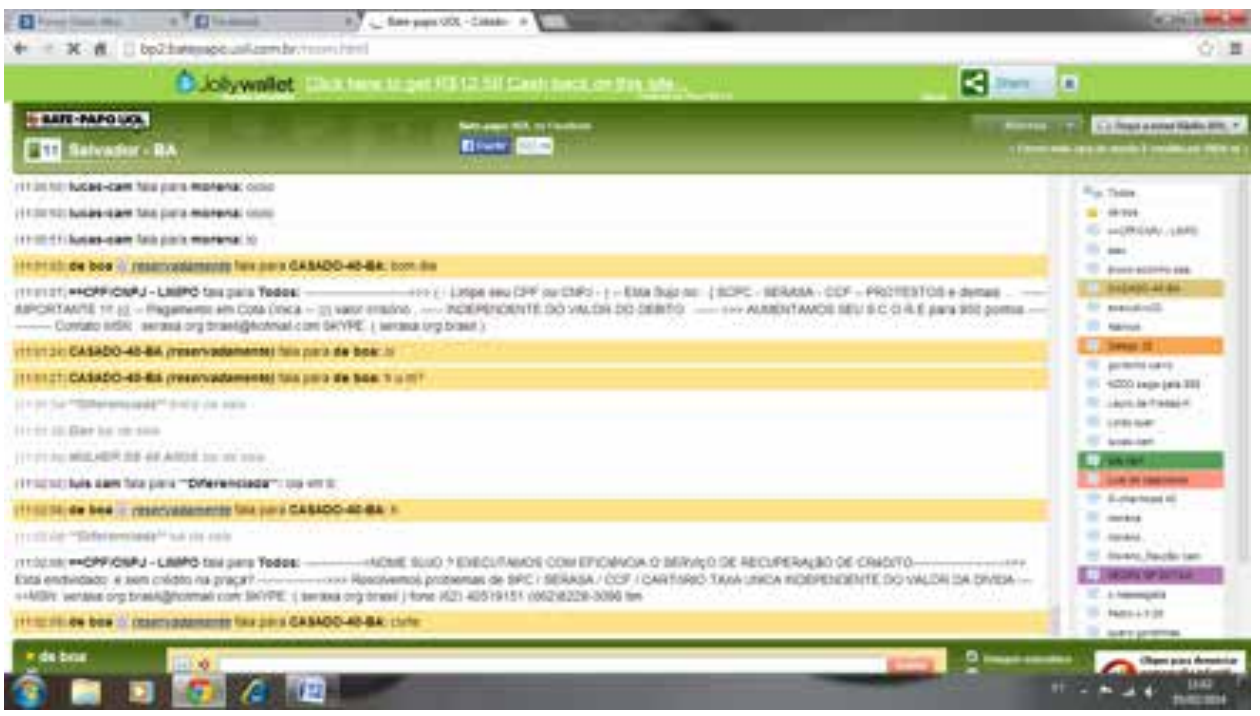

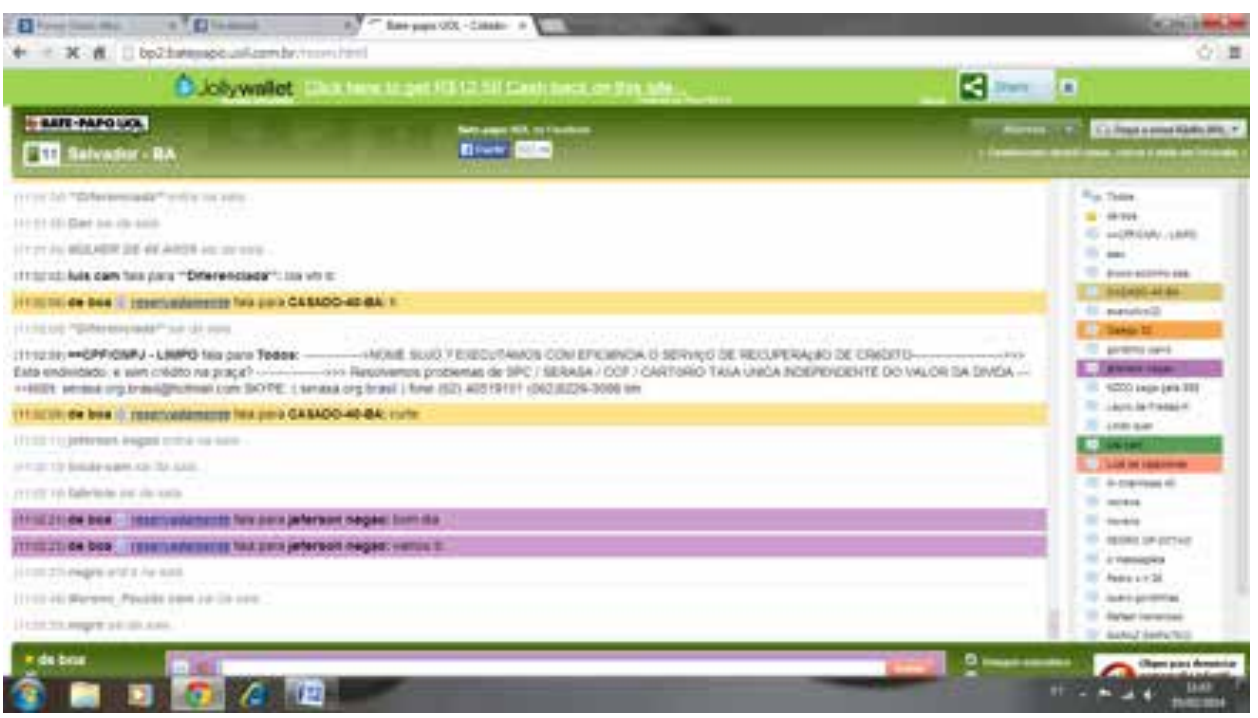




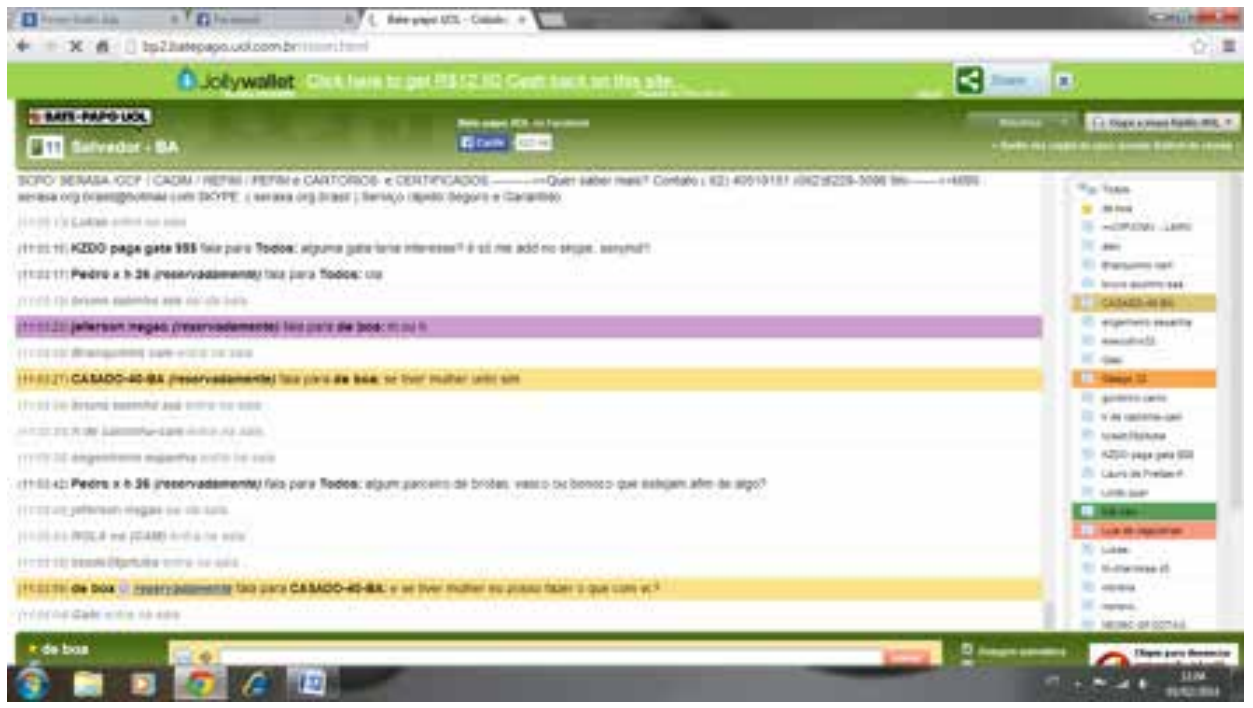

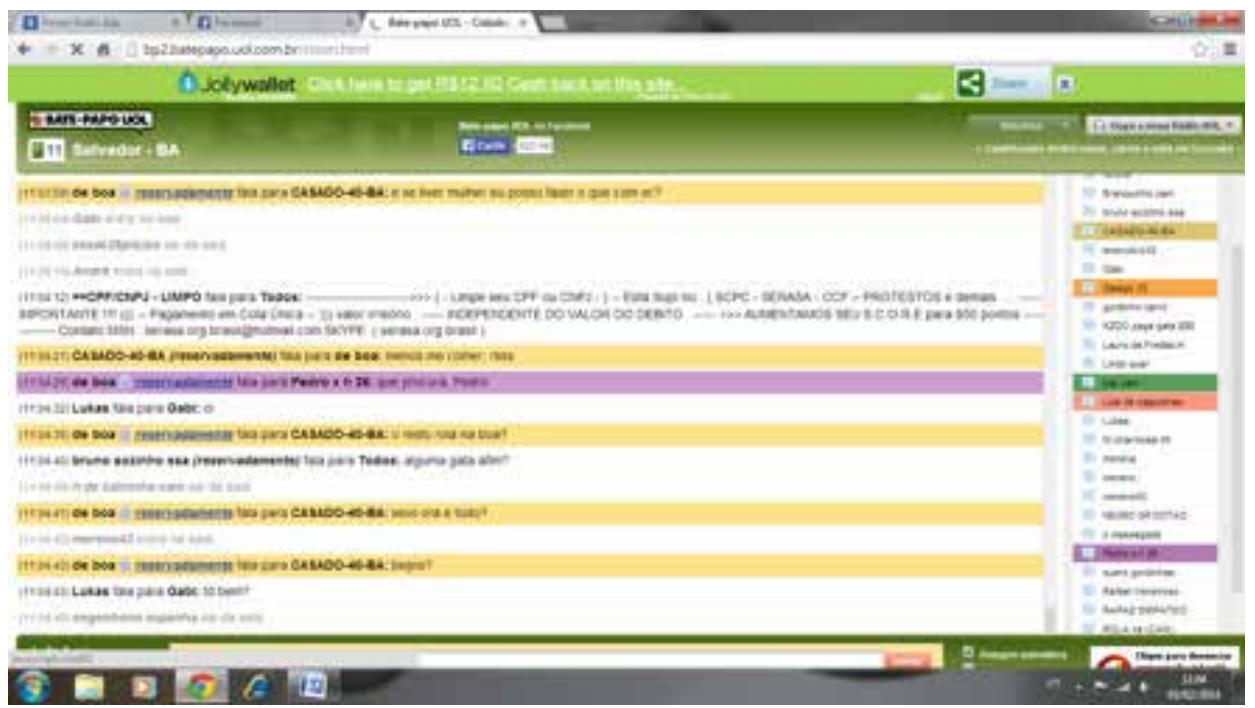

